\title{
Overactive bladder and caffeine: comparing women with and without mental health diagnoses
}

Vidyah Chakravarthy, Margaret Tolbert, Caroline Garcia and Janis Miller

\section{ABSTRACT}

Caffeine is a stimulant thought to activate the pleasure centre in the brain, commonly used in the general public for purposeful attempt to alter mood, and also commonly perceived to be a bladder irritant with associated urgency and frequency symptoms. Mental health diagnosis, such as depression, is also associated with overactive bladder. Taken together, it is plausible that women with overactive bladder symptoms along with comorbid mental health symptoms may also show higher caffeine intake but no data exist. This pilot study's purpose was to determine in women with overactive bladder, if those with a mental health diagnosis (we included anxiety, depression, post-traumatic stress disorder and bipolar diagnosis) consume a significantly higher amount of caffeine than those without any of these diagnoses. Secondary analysis was performed on data from women with overactive bladder recruited into a longitudinal parent study on beverage management. All parent study participants met criteria of urgency and voiding more than seven times per day. Each kept a detailed 3-day diary of beverage intake. From the total parent study pool of 61 , we identified 14 women with a comorbid mental health diagnosis as described above and 47 without when interviewed at baseline. Women with mental health diagnosis demonstrated higher median baseline caffeine intake per day than their counterparts without mental health diagnosis: $240.2 \mathrm{mg}$ (range: $72.3-576.0 \mathrm{mg}$ ) versus $174.3 \mathrm{mg}$ (range: $0-567.6 \mathrm{mg}$ ), which was marginally significant $(p=.053)$. Volume of caffeinated beverage intake did not differ significantly. In women with overactive bladder and comorbid mental health symptoms, higher caffeine intake may be a previously unrecognized link. Cause and effect is unknown between the three conditions of overactive bladder, mental health disorders and higher caffeine intake; but this initial data support the need for further research.

Key words: Caffeine $\bullet$ Continence $\bullet$ Mental health diagnosis • Overactive bladder $\bullet$ Urinary incontinence $\bullet$ Woman's health

\section{BACKGROUND}

It is a common practice among health care providers to relate overactive bladder $(\mathrm{OAB})$ symptoms to excess consumption of caffeine. A typical first-line treatment for women presenting to their health care providers with $O A B$ is to decrease or eliminate caffeinated beverages. Although data linking caffeine to $O A B$ symptoms are sparse, there is an abundance of expert advice to decrease or eliminate caffeine, for instance as published on well-respected websites: 'National Association for Continence' (NAFC, 2008); 'Cleveland

Authors: V Chakravarthy; M Tolbert; C Garcia; J Miller; University of Michigan, Ann Arbor, MI, USA

Address for correspondence: J Miller, School of Nursing, Division 2, 400 N. Ingalls, Ann Arbor, MI 48109-5482, USA.

E-mail: janismm@umich.edu
Clinic' (2008); 'National Institute for Clinical Excellence' (NICE, 2006).

Data show that higher rates of bladder disorders (voiding frequency, urgency and incontinence) are linked with mental health conditions (Zorn et al., 1999; Weissman et al., 2000; Nygaard et al., 2003; Melville et al., 2005; Moghaddas et al., 2005; Fitzgerald et al., 2007; Link et al., 2007), though the underlying mechanism involved is not understood. Causal factors suggested include some alteration stemming from sexual abuse (Link et al., 2007), a candidate gene (Weissman et al., 2000), and noradrenaline and serotonin dysregulation (DeGroat, 2002). None of these explanations completely explain the linkage between bladder disorders and mental health conditions. 
A tenable companion hypothesis is that $O A B$ and mental health diagnoses are linked in part by caffeine, one of the world's most popular mood-altering drugs. Caffeine is known to activate the pleasure centre in the brain (Kelly and Mac Evilly, 2001; Lorist and Tops, 2003). Thus, it is reasonable to assume that caffeine, a readily available and socially accepted drug, could be used as a form of self-medication for those experiencing mood disorders. If so, and if caffeine is also a bladder irritant, then women with a mental health diagnosis may inadvertently trigger or exacerbate symptoms of OAB, symptoms which might otherwise not exist at clinically significant levels.

\section{RESEARCH QUESTION}

To begin to explore this possible connection, we performed a small pilot study using data available from a longitudinal parent study on beverage management as treatment for OAB. Using only the baseline data from the parent study, we tested the hypothesis that women with comorbid $\mathrm{OAB}$ and mental health diagnoses would demonstrate higher caffeine intake on 3-day diaries than those with $\mathrm{OAB}$ alone.

\section{SAMPLE}

The parent study (analysis of longitudinal data is ongoing) recruited 61 community-dwelling women through newspaper advertising after obtaining Institutional Review Board (IRB) approval. Inclusion criteria included: female, age 18 and older, greater than seven voids per day or two per night, daily consumption of at least 16 ounces of beverages potentially irritating to the bladder (coffee, tea, alcohol or caffeinated beverages), greater than 32 ounces of overall beverage intake per day, and an answer of 'yes' to the question, 'Do you experience frequent, strong feelings of urgency to empty your bladder?' Exclusion criteria included women who were pregnant, had diabetes, were taking diuretic pills, and women who experienced pain when urinating or had frequent urinary tract infections. In addition, women who had surgery for incontinence within the past year could not participate because of the likelihood of the surgical procedure causing the symptoms of OAB. Cognitively impaired adults were excluded because of the difficulty in diary keeping and consistency in educational delivery. Informed consent was obtained and participants enrolled.

The study design for this secondary analysis of baseline data was retroactive case control. We retrospectively assigned women as 'cases' if baseline data from the parent longitudinal study included a diagnosis of one of the following mental health diagnoses: anxiety, depression, post-traumatic stress disorder or bipolar disorder $(23 \%, n=14)$, or if medications indicated the same. Those women from the parent study without a mental health diagnosis served as controls $(77 \%, n=47)$.

\section{DATA COLLECTION METHODS}

Upon entry into the longitudinal parent study, women were given a DVD as well as written instructions on how to keep a detailed 3-day diary at home and were instructed to be as specific as possible. They were given precise examples on how to record beverage intake on their diary (e.g. Starbucks caffeinated coffee, grande 16 ounces). Food intake was not recorded, so only data on caffeine consumed through beverages were available for analysis. The diary form used was designed for the parent study and is appended (Appendix A). The parent intervention study requires data on both intake and bladder and bowel output, as well as symptom change measured by $O A B$ questionnaires (Bower et al., 2001; Coyne et al., 2002; de Wachter, 2003). Although women from the parent study completed three 3-day diaries, only the intake data from the baseline diary were utilized for analysis in this report.

A nurse practitioner gathered additional information in a clinical setting through an interview and questionnaires, including information about each subject's past and current medical diagnoses, medications, and demographics; height and weight were measured. Participants were assigned identification numbers to preserve anonymity.

\section{DATA ANALYSIS}

The secondary analysis represented here was conducted as pilot information to determine worthiness of future investigation on the potential linkage between caffeine, mental health conditions and $O A B$.

Data management of the baseline 3-day intake portion of the participants' diaries for this analysis was conducted as follows. Caffeine was quantified in milligrams using a variety of sources to obtain precise content calculations. Primarily, we relied on USDA data and specific brand websites (Coca-Cola, Pepsi, Folgers, etc.). Details of caffeine conversions by product are appended (Appendix B). Three-day tallies of caffeine intake in milligrams, caffeinated beverage intake in ounces and total beverage intake in ounces were all reduced to daily averages. Descriptive analysis was used to characterize the sample and graphical portrayal of the data provided additional information. Scatter-plots were used to examine data on age or body mass index (BMI) in relation to caffeine intake.

For hypothesis testing, distribution free statistics were used when data were not normally distributed. 
The non-parametric Mann-Whitney $U$ test was used to test for differences in caffeine intake, measured in milligrams, between women with and without a mental health diagnosis and an independent $t$-test was used to determine whether volume of caffeinated beverage intake, measured in ounces, differed between groups. A $p$-value of .05 was used to determine significance. A priori power analysis was not conducted as we relied on the fixed sample size of the parent study that was primarily designed for longitudinal analysis.

\section{RESULTS}

The women were on average 48 years old, ranging from 20 to 88 years, and $87 \%$ were Caucasian, $59 \%$ had at least one vaginal delivery and $65 \%$ had a college education. All women met $O A B$ criteria of voiding greater than seven times per day and/or greater than two times per night and said 'yes' on entrance screening to the question 'Do you experience frequent, strong feelings of urgency to empty your bladder?' The daily average of milligrams of caffeine intake was $205.1 \mathrm{mg}$ (standard deviation =140.8). Amount of caffeine intake in relation to age and BMI are portrayed graphically in Figures 1 and 2 .

To display the data according to cases and controls, Figure 3 shows box plots of caffeine intake

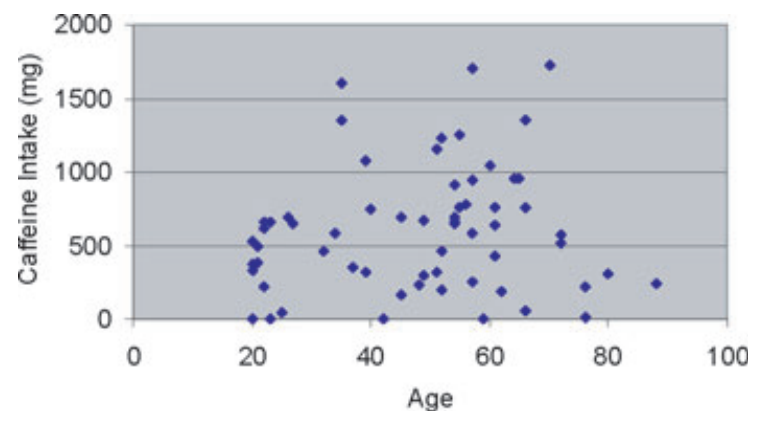

Figure 1 The scatter-plot shows that caffeine intake and age do not appear to correlate in this sample.

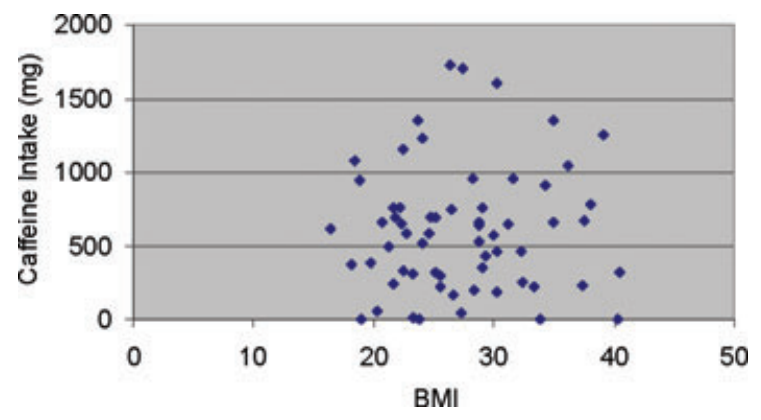

Figure 2 The scatter-plot shows that caffeine intake and body mass index (BMI) do not appear to correlate in this sample. in milligrams. The median (range) of caffeine intake for cases was 240.2 (72.3-576.0) mg per day, whereas for controls it was $174.3(0-567.6) \mathrm{mg}$ per day: a marginally significant difference in this small sample size $(U=216, z=-1.9, p=.053)$. Volume of caffeinated beverage intake (mean \pm SD ounces) did not differ statistically between those with and without a mental health diagnosis $(77.1 \pm 20.7$ versus 70.4 \pm 24.3 ounces, respectively, $p=.36$ ), but the trend towards higher volume in the group with a mental health diagnosis suggests this may be a limitation of our sample size.

\section{DISCUSSION}

This study showed that women with a diagnosis of depression, anxiety, post-traumatic stress disorder or bipolar disorder and who have concomitant OAB may have a disproportionate intake of caffeine (approximately $33 \%$ more in this study) when compared to women with similar OAB symptoms but without a mental health diagnosis. The women with a mental health diagnosis studied here, preferentially selected more highly caffeinated drinks as their beverage of choice, perhaps to positively affect mood.

Results of this small pilot work should be interpreted with caution, but this initial investigation provides beginning support for our working hypothesis that caffeine, mental health conditions and $O A B$ may be linked. To our knowledge, this is the first time that this link has been addressed with data. This may be because collecting data at the level of precision needed is difficult and burdensome. This study, despite being small and a secondary analysis, had the advantage of quantifying caffeine intake with far greater detail than usually obtained on standard voiding diaries, thus allowing more exact calculation of caffeine consumption. Even with this higher precision, caffeine sources from food, for instance a chocolate bar, were not included, so the estimate of actual caffeine intake may still be low.

We reiterate that the parent study was not fully powered to address this secondary research question, and the data should be considered pilot with limited generalizability until findings are confirmed by additional research. In addition, study groups may not have been pure; for instance, those placed in the control group may have actually had a mental health problem, but had not sought help from a health care provider, and as such did not have a formal diagnosis. We also did not extensively investigate the relationship between medications taken by the women with mental health diagnoses, which may have differed from those without diagnoses, and could possibly have 


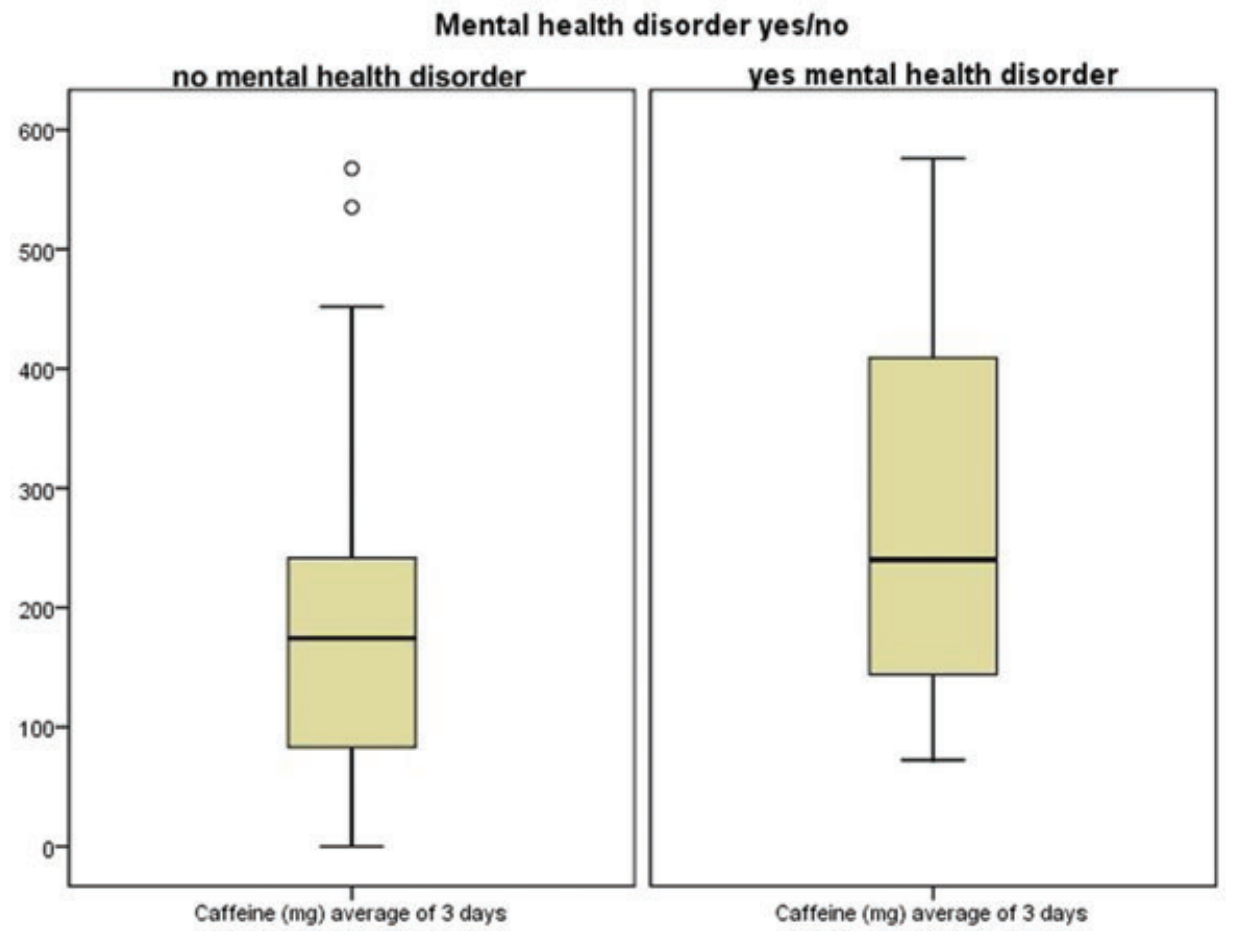

Figure 3 Boxplots showing 3-day average of caffeine intake in milligrams by cases (subjects who had a mental health diagnosis) and controls.

influenced beverage intake, for instance in response to side-effects, such as dry mouth. However, there were no significant differences observed between the volumes of total beverage intake in the two study groups, suggesting volume increase alone was not the contributing factor for $\mathrm{OAB}$ in women with mental health diagnoses. Our study also did not describe the caffeine intake profile before the onset of symptoms of either depression or $\mathrm{OAB}$ and the retrospective design does not allow determination of cause and effect.

\section{CONCLUSION}

Although replication of the findings is warranted, this initial pilot work provides the first data, to our knowledge, that caffeine intake may by higher in women with mental health conditions and might inadvertently produce or exacerbate symptoms of OAB.

\section{REFERENCES}

Bower W, Moore K, Adams R. (2001). A pilot study of the home application of transcutaneous neuromodulation in children with urgency or urge incontinence. The Journal of Urology; 166: 2420-2422.

Cleveland Clinic (2008). Health Information: Overactive Bladder Treatment. http://my.clevelandclinic.org/disorders/over active_bladder/urology_treatment.aspx (accessed 2/10/08).

Coyne K., Revicki D, Hunt T, Corey R, Stewart W, Bentkover J, Kurth H, Abrams P. (2002). Psychometric validation of an

\section{WHAT IS KNOWN ABOUT THIS TOPIC}

- Urologic symptoms are associated with mental health diagnoses such as depression.

- Caffeine intake is commonly thought to instigate OAB symptoms.

- Caffeine is a stimulant commonly used in society to boost mood.

\section{WHAT THIS PAPER ADDS}

- Our pilot data support the hypothesis that women who have overactive bladder and a concomitant mental health diagnosis consume higher amounts of caffeine than women with $O A B$ and without a mental health diagnosis.

- This finding has implications for prevention and treatment of $O A B$ in women with mental health diagnosis through management of caffeine consumption. 
overactive bladder symptom and health-related quality of life questionnaire: the OAB-q. Quality of Life Research; 11: 563-574.

DeGroat WC. (2002). Influence of central serotonergic mechanism on lower urinary tract function. Urology; 59(Suppl): 30-36.

de Wachter S, Wyndaele JJ. (2003). Frequency-volume charts: a tool to evaluate bladder sensation? Neurourology and Urodynamics; 22: 638-642.

Fitzgerald MP, Link CL, Litman HJ, Travison TG, McKinaly JB. (2007). Beyond the lower urinary tract: the association of urologic and sexual symptoms with common illnesses. European Urology; 52: 407-415.

Kelly C, Mac Evilly C. (21 May 2001). Mood and Food. British Nutrition Foundation, National Heart and Lung Institute, London; 325-329.

Link CL, Lutfey KE, Steers WD, McKinlay JB. (2007). Is abuse causally related to urologic symptoms? Results from the Boston Area Community Health (BACH) Survey. European Urology; 52: 397-406.

Lorist M, Tops M. (2003). Caffeine, fatigue, and cognition. Brain and Cognition; 53: 82-94.

Melville JL, Delaney K, Newton K, Katon W. (2005). Incontinence severity and major depression in incontinent women. Obstetrics and Gynecology; 106: 585-592.

Moghaddas F, Lidfeldt J, Nerbrand C, Jernstrom H, Samsioe G. (2005). Prevalence of urinary incontinence in relation to self-reported depression, intake of serotonergic antidepressants, and hormone therapy in middle-aged women: a report from the Women's Health in the Lund Areas study. Menopause: The Journal of the North American Menopause Society; 12: 318-324.

NAFC: National Association for Continence. (2008). Urge urinary incontinence/overactive bladder. http://www. nafc.org/bladder-bowel-health/types-of-incontinence/urgeincontinence/\#UrgeTreatment (accessed 22/10/08).

NICE: National Institute for Clinical Excellence. (October, 2006) Urinary incontinence: the management of urinary incontinence in women. http://www.nice.org.uk/nice media/pdf/word/CG40ung1006.pdf (Accessed 16 October 2009).

Nygaard I, Turvey C, Burns TL, Crischelles E, Wallace R. (2003). Urinary incontinence and depression in middle-aged United States women. Obsteterics and Gynecology; 101: 149-156.

Weissman M, Fyer A, Haghighi F, Heiman G, Deng Z, Hen R, Hodge S, Knowles J. (2000). Potential panic disorder syndrome: clinical and genetic linkage evidence. American Journal of Medical Genetics (Neuropsychiatric Genetics); 96: 24-35.

Zorn BH, Montgomery H, Pieper K, Gray M, Steers WE. (1999). Urinary incontinence and depression. Journal of Urology; 162: 82-84. 
APPENDIX A

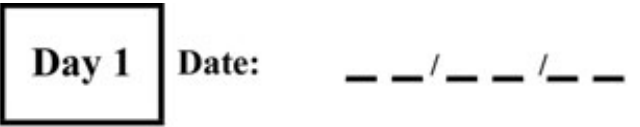

Time Arise:

Time to Bed :

\section{Beverage Intake}

\begin{tabular}{|c|c|c}
\hline \multirow{E}{*}{} & $\begin{array}{c}\text { Beverage Type } \\
\text { \& Brand } \\
\text { Be as specific as } \\
\text { possible }\end{array}$
\end{tabular}

(c.g. diet decaf Dr. Pibb) $\mathrm{am} / \mathrm{pm}$

$\mathrm{am} / \mathrm{pm}$

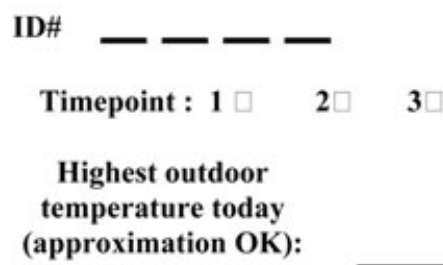

(approximation $\mathrm{OK})$ :

\begin{tabular}{|l|l|l|l|l|}
\hline & (c.g. diet decaf Dr. Pibb) & Y/N & Amount & \\
\hline & & & & \\
\hline & & & & \\
\hline & & & & \\
\hline
\end{tabular}

I added
Artificial

Sweetener

\begin{tabular}{|c|} 
\\
Beverage \\
Amount \\
(ounces)
\end{tabular}

\begin{tabular}{|c|c|c|c|c|c|}
\hline \multicolumn{5}{|c|}{ Urine Output } & \multirow[b]{2}{*}{ BMs } \\
\hline \multicolumn{4}{|c|}{ Volume of Urine Output } & $\begin{array}{c}\text { Episodes } \\
\text { of }\end{array}$ & \\
\hline $\begin{array}{c}\text { Urine } \\
\text { Amount } \\
(\mathrm{oz})\end{array}$ & $\begin{array}{c}\text { Measured } \\
\checkmark\end{array}$ & $\begin{array}{c}\text { Close } \\
\text { estimate } \\
\checkmark\end{array}$ & $\begin{array}{c}\text { Wild } \\
\text { Guess } \\
\checkmark \\
\end{array}$ & $\checkmark$ & $\checkmark$ \\
\hline & & & & & \\
\hline & & & & & \\
\hline & & & & & \\
\hline & & & & & \\
\hline & & & & & \\
\hline & & & & & \\
\hline & & & & & \\
\hline & & & & & \\
\hline & & & & & \\
\hline & & & & & \\
\hline & & & & & \\
\hline & & & & & \\
\hline & & & & & \\
\hline & & & & & \\
\hline & & & & & \\
\hline & & & & & \\
\hline & & & & & \\
\hline & & & & & \\
\hline & & & & & \\
\hline & & & & & \\
\hline & & & & & \\
\hline & & & & & \\
\hline & & & & & \\
\hline & & & & & \\
\hline & & & & & \\
\hline & & & & & \\
\hline & & & & $\mathrm{Mo}$ & $\begin{array}{l}\text { Bowel } \\
\text { ements }\end{array}$ \\
\hline
\end{tabular}


Day 1

\section{Food Diary}

\begin{tabular}{|c|c|c|c|c|c|c|c|}
\hline Time & $\begin{array}{c}\text { Foods } \\
\text { Consumed }\end{array}$ & $\begin{array}{l}\text { Amount } \\
\text { (ounces) }\end{array}$ & $\begin{array}{c}\text { Meas- } \\
\text { ured } \\
\checkmark\end{array}$ & $\begin{array}{l}\text { Close } \\
\text { estimate } \\
\checkmark\end{array}$ & $\begin{array}{l}\text { Wild } \\
\text { Guess } \\
\checkmark\end{array}$ & $\begin{array}{c}\text { Preparation } \\
\text { Method }\end{array}$ & Comments \\
\hline & & & & & & & \\
\hline & & & & & & & \\
\hline & & & & & & & \\
\hline & & & & & & & \\
\hline & & & & & & & \\
\hline & & & & & & & \\
\hline & & & & & & & \\
\hline & & & & & & & \\
\hline & & & & & & & \\
\hline & & & & & & & \\
\hline & & & & & & & \\
\hline & & & & & & & \\
\hline & & & & & & & \\
\hline & & & & & & & \\
\hline & & & & & & & \\
\hline & & & & & & & \\
\hline & & & & & & & \\
\hline & & & & & & & \\
\hline & & & & & & & \\
\hline & & & & & & & \\
\hline & & & & & & & \\
\hline
\end{tabular}


Day 1

ID

Timepoint : $1 \square \quad 2 \square \quad 3 \square$

\begin{tabular}{|c|c|c|l|}
\hline Today & Type of Exercise & \multicolumn{1}{|c|}{ Time Spent } & \multicolumn{1}{c|}{$\begin{array}{c}\text { Intensity (optional) } \\
220 \text {-age = maximum heart rate (MHR) }\end{array}$} \\
\hline Your Exercise pattern was: & & & $\square$ Low (50-60\% MHR) \\
& & $\begin{array}{l}\text { Medium }(60-75 \% \text { MHR) } \\
\text { High }(75-80 \% \text { MHR) }\end{array}$ \\
\hline
\end{tabular}

"Typically, when you needed to go to the bathroom during waking hours today you could (Circle one):

\begin{tabular}{|c|c|c|c|c|}
\hline $\begin{array}{c}\text { Make the urge go } \\
\text { away }\end{array}$ & Easily hold on & Wait a little while & Hardly wait & $\begin{array}{c}\text { Feel the urine already } \\
\text { coming out }\end{array}$ \\
\hline 1 & 2 & 3 & 4 & 5 \\
\hline
\end{tabular}

Typically, when you needed to go to the bathroom during sleeping hours today you could ( Circle one):

\begin{tabular}{|c|c|c|c|c|}
\hline $\begin{array}{c}\text { Make the urge go } \\
\text { away }\end{array}$ & Easily hold on & Wait a little while & Hardly wait & $\begin{array}{c}\text { Feel the urine already } \\
\text { coming out }\end{array}$ \\
\hline 1 & 2 & 3 & 4 & 5 \\
\hline
\end{tabular}

\begin{tabular}{|l|c|c|c|c|c|c|}
\hline${ }^{+}$Today, how bothered were you by... & $\begin{array}{c}\text { Not at } \\
\text { all }\end{array}$ & $\begin{array}{c}\text { A little } \\
\text { bit }\end{array}$ & $\begin{array}{c}\text { Some } \\
\text { what }\end{array}$ & $\begin{array}{c}\text { Quite } \\
\text { a bit }\end{array}$ & $\begin{array}{c}\text { A } \\
\text { great } \\
\text { deal }\end{array}$ & $\begin{array}{c}\text { A very } \\
\text { great } \\
\text { deal }\end{array}$ \\
\hline 1. Frequent urination during daytime hours & 1 & 2 & 3 & 4 & 5 & 6 \\
\hline 2. An uncomfortable urge to urinate & 1 & 2 & 3 & 4 & 5 & 6 \\
\hline 3. A sudden urge to urinate with little or no warning & 1 & 2 & 3 & 4 & 5 & 6 \\
\hline 4. Accidental loss of small amounts of urine & 1 & 2 & 3 & 4 & 5 & 6 \\
\hline 5. Nighttime urination & 1 & 2 & 3 & 4 & 5 & 6 \\
\hline 6. Waking up at night because you had to urinate & 1 & 2 & 3 & 4 & 5 & 6 \\
\hline 7. An uncontrollable urge to urinate & 1 & 2 & 3 & 4 & 5 & 6 \\
\hline 8. Urine loss associated with a strong desire to urinate & 1 & 2 & 3 & 4 & 5 & 6 \\
\hline
\end{tabular}

${ }^{\ddagger}$ When you urinated today, what was your usual perception of your bladder fullness?

\begin{tabular}{|l|l|}
\hline $\mathbf{0}$ & No bladder sensation \\
\hline $\mathbf{1}$ & Urinating could easily be delayed for more than $30-60$ minutes \\
\hline $\mathbf{2}$ & Urinating could only be delayed for 30 minutes \\
\hline $\mathbf{3}$ & Urinating could only be delayed for 5 minutes \\
\hline 4 & Immediate urinating was mandatory and/or fear of leakage \\
\hline
\end{tabular}

Did overactive bladder symptoms disturb your sleep last night?

\begin{tabular}{|c|c|c|}
\hline None & Some & A lot \\
\hline
\end{tabular}

Visual analogue scale adapted from Bower, Moore, and Adams, 2001

Coyne, 2002

${ }^{2}$ De Wachter S, 2003 


\section{APPENDIX B}

Caffeine Calculations:

1. Coffee:

a. USDA documents $12 \mathrm{mg}$ per ounce for "Coffee, brewed from grounds, prepared with tap water."

b. Many other sites quoted other amounts depending on brand, origin of coffee, degree of roasting.

2. Decaf Coffee: USDA: "Coffee, brewed from grounds, prepared with tap water, decaffeinated" $=0 \mathrm{mg}$ per ounce, $2 \mathrm{mg}$ per 8 ounces, $\cdot 25 \mathrm{mg}$ per ounce.

3. Coffee: $1 / 2$ decaf, $1 / 2$ caf: $6.125 \mathrm{mg}$ per ounce, per averaging the USDA caf with decaf.

4. Instant Coffee:

a. USDA: "Coffee, instant, regular, prepared with water" $8 \mathrm{mg}$ per ounce.

5. Coke: per coca-cola website:

a. Coca-Cola classic: $23 \mathrm{mg}$ per 8 ounces, $2.875 \mathrm{mg}$ per ounce.

b. Decaf Coke: $0 \mathrm{mg}$ per 8 ounces.

c. Diet Coke: $31 \mathrm{mg}$ per 8 ounces, $3.875 \mathrm{mg}$ per ounce.

6. Root Beer:

a. Barqs (per coca-cola website) $15 \mathrm{mg}$ per 8 ounces, diet barqs $\&$ barq's crème sodas $=0 \mathrm{mg}$ per 8 ounces.

7. Pepsi: (Per Pepsi website) $25 \mathrm{mg}$ per 8 ounces, $3.125 \mathrm{mg}$ per ounce.

a. Diet Pepsi: $35 \mathrm{mg}$ per 12 ounces, $2.917 \mathrm{mg}$ per ounce.

b. Diet and Reg Mt Dew: $54 \mathrm{mg}$ per 12 ounces.

8. Green Tea (not found in USDA):

a. Mayo Clinic: 8 ounces $=30-50 \mathrm{mg}$ (Source: Center for Science in the Public Interest, 2007; The Coca-Cola Co., 2007; PepsiCo Inc., 2007; Starbucks Corp., 2007; USDA National Nutrient Database for Standard Reference, 2007). I will round and say $40 \mathrm{mg}$ per 8 ounces, or $5 \mathrm{mg}$ per ounce.

9. Black Tea:

a. 42-72 mg per 8 ounces. Average: 57 per 8 ounces, $7.125 \mathrm{mg}$ per ounce Source: Astill C, Birch MR, Dacombe C, Humphrey PG, Martin PT. Factors affecting the caffeine and polyphenol contents of black and green tea infusions. J Agric Food Chem. 2001;49(11):5340-5347. (PubMed)

10. Chocolate Milk:

a. USDA: "Chocolate syrup, prepared with whole milk" $=6 \mathrm{mg}$ per 8 ounces, $.75 \mathrm{mg}$ per ounce.

11. Hot chocolate:

a. USDA: "Cocoa mix, powder, prepared with water" $=1 \mathrm{mg}$ per ounce.

12. Folgers (From website)
a. Instant: $74 \mathrm{mg}$ per 6ounces: $12.33 \mathrm{mg}$ per ounce.
b. Regular: $59 \mathrm{mg}$ per 6 ounces: $9.83 \mathrm{mg}$ per ounce
c. Half-caff: $30 \mathrm{mg}$ per 6 ounces: $5 \mathrm{mg}$ per ounce.
d. Decaf: $2.8 \mathrm{mg}$ per 6 ounces: $0.467 \mathrm{mg}$ per ounce.

13. Tea:

a. USDA: "Tea, brewed, prepared with tap water" $=6 \mathrm{mg}$ per ounce.

b. USDA: "Tea, brewed, prepared with tap water, decaffeinated" $=0 \mathrm{mg}$ per ounce.

i Visual analogue scale adapted from Bower, Moore, and Adams, 2001.

ii Coyne, 2002

iii De Wachter S, 2003 